\title{
Career prospects in general surgery in England and Wales
}

\author{
THOMAS C B DEHN， DULCIE GOODING， M H GOUGH
}

The joint manpower initiative by the Department of Health and Social Security and the Joint Consultants Committee provides the latest and perhaps the most hopeful stimulus to solve the problems of medical manpower in the acute hospital services. ${ }^{1}$ It has been recognised for some time that career prospects for junior doctors in the acute medical and surgical specialties have become intolerable. ${ }^{2}$ In general surgery the once orderly career structure has deteriorated, resulting in a surfeit of over trained and expensively trained "junior" surgeons unable to obtain career appointments.

This paper emphasises the importance of the new proposals and should help intending surgeons to calculate their chances of future employment. We also hope that it will encourage both senior and junior members of the profession to respond to the requests made by the authors of the manpower initiative that opinions be offered soon in order that a final plan may be agreed in the near future.

\section{Some recent trends}

Under the existing system it has been recommended that a consultant in general surgery should ideally gain appointment by the age of $35,{ }^{3}$ even allowing for the two years now commonly spent undertaking a research fellowship (table I). ${ }^{4}$ Between 1973 and 1983 , however, the mean age on appointment to a general surgical consultancy in England and Wales rose from $37 \cdot 1$ to $38 \cdot 1$ years and the mean time spent as a senior registrar increased from $3 \cdot 1$ to 5.5 years. ${ }^{56}$ Not surprisingly, in 1985 nine of the $37(24 \%)$ general surgical consultant appointments were of applicants aged 40-49 (personal communication).

\section{The pyramid and the competition}

In 1984 the general surgical consultant establishment in England and Wales, including honorary contracts, numbered $947 .^{7} \mathrm{At}$ present the expected number of annual consultant and academic retirement vacancies at age 65 for the next decade is $36 .^{7}$ The 197 senior registrar and lecturer posts accredited for higher surgical training in 1985 are controlled by the specialist advisory committee in general surgery ${ }^{8}$ Retrospective recognition of previous registrar or research work allows accreditation and therefore eligibility for a consultant appointment after three years in a higher surgical training programme.

Promotion into a higher surgical training post is by fierce competition and is now usually preceded by a full time research post. ${ }^{4}$ Before this decade a period of research was often incorporated into a senior registrar post. The number of trainees in research posts

\section{John Radcliffe Hospital, Oxford OX3 9DU}

THOMAS C B DEHN, MS, FRCS, clinical lecturer in surgery, Nuffield Department of Surgery

\section{Oxford Regional Health Authority, Oxford OX3 7LF}

DULCIE GOODING, MB, FFCM, specialist in community medicine

Correspondence to: Mr Dehn. before they achieve higher surgical training status is not recorded in DHSS manpower statistics. A recent survey by one of us (TD), however, identified 153 such surgeons occupying full time general surgical research posts, solely in the United Kingdom, and acknowledged that this number was an underestimate. ${ }^{9}$ Respondents to that questionnaire spent a mean of $2 \cdot 1$ years in research, and $81 \%$ of them would seek or were seeking promotion into a higher surgical training post.

According to DHSS statistics, there are 668 registrars and 628 senior house officers in general surgical posts in England and Wales. ${ }^{7}$ Senior house officer posts should probably be regarded as part of general professional training, but acceptance of a registrar post in surgery implies a wish to continue in that specialty. Up to $40 \%$ of such registrars do not become senior registrars. ${ }^{10}$

TABLE I-Present model career pathway of the intending general surgeon *

\begin{tabular}{lcc}
\hline Grade & $\begin{array}{c}\text { Length in } \\
\text { post } \\
\text { (years) }\end{array}$ & $\begin{array}{c}\text { Age on } \\
\text { appointment } \\
\text { (years) }\end{array}$ \\
\hline Consultant & 30 & 35 \\
Senior registrar & 4 & 31 \\
Research registrar & 2 & 29 \\
Registrar & $2-3$ & 26 \\
Senior house officer & 2 & 24 \\
Preregistration house officer & 1 & 23 \\
\hline
\end{tabular}

${ }^{\star}$ Modified from the Royal College of Surgeons' Second report on surgical manpower and the career structure. ${ }^{3}$

Because of the financial restrictions recently imposed on bsth health authorities and universities a proportion of consultant posts has been frozen, whether newly approved or vacated by retirement.

As the number of higher surgical training posts is currently fixed at 197 the rate of entry into such posts must equal the rate of promotion of senior registrars into consultant posts. Thus only about 36 senior registrar and registrar/research registrars can be promoted annually into consultant and higher surgical training posts respectively. In reality, with only about 36 senior registrars a year gaining a consultancy those already accredited but unable to achieve promotion remain in post. Consequently, those research registrars unable to move into a senior registrar post either undertake further research or return to a middle grade registrar post, thus diminishing the chances of promotion for those in grades below.

Table II shows the current establishment and predicted requirements for general surgical staffing in England and Wales in the absence of any further consultant expansion. Under the present system to obtain an orderly career structure for those entering the specialty at registrar level the required manpower establishment of each grade can be calculated by multiplying the mean number of years spent in each post by 36 (the annual number of retirement consultant vacancies). This total could obviously be increased to take account of extra consultant posts created by factors such as early retirement. At present there is an excess of those in post over those able to obtain career appointments. In future planning the required establishment of the training grades could reasonably be 
TABLE II-Required and actual staffing levels for general surgery in England and Wales, without further consultant expansion

\begin{tabular}{lcccc}
\hline Grade & $\begin{array}{c}\text { Retirement } \\
\text { vacancies year }\end{array}$ & $\begin{array}{c}\text { Average } \\
\text { duration of post } \\
\text { (years }\end{array}$ & $\begin{array}{c}\text { Required } \\
\text { career } \\
\text { establishment }\end{array}$ & $\begin{array}{c}\text { In post } \\
1984-5\end{array}$ \\
\hline Consultant & 36 & 30 & 1080 & 947 \\
Senior registrar & 36 & 4 & 144 & 197 \\
Research registrar & 36 & 2 & 72 & $150^{\star}$ \\
Registrar & 36 & 3 & 108 & 668 \\
\hline
\end{tabular}

^Approximate.

increased by $10-20 \%$, depending on the grade, to allow for natural wastage and movement into specialties other than general surgery and to provide an element of competition.

Regional health authorities have published their strategic plans for the decade 1984-94, and regional manpower planning for each specialty may be obtained from these plans. For example, in the Oxford region there are 10 general surgical higher surgical training posts, six in Oxford and four in district general hospitals, in posts rotating with London teaching hospitals. In the decade covered by this plan there will be 100 post years and, with a reasonable occupancy in a general surgical higher surgical training post of four years, about 25 senior registrars in general surgery will be trained and eligible for consultancy. The Oxford Regional Health Authority's strategic plan has identified 13 general surgical consultant vacancies (seven retirement and six new posts). Consequently only half of those senior registrars trained will be able to find career posts in the region of their training. These figures can be variously interpreted. The region is $(i)$ overproducing surgical senior registrars by a half; (ii) creating one third of the number of new consultant posts that are required; or (iii) expected to be a net supplier of consultant general surgeons to other regions.

\section{Future}

Johnson has described the problems of hospital staffing and career structure as "the cycle of gloom," with an endless spiral of ineptitude of both the government and medical profession to enact a solution. ${ }^{11}$ Expansion of the consultant numbers, as recommended by the Short report, ${ }^{12}$ has not occurred, seemingly because of concern of senior members of the profession that it would result in "a reduced case load per consultant and changed case-mix, leading to a loss of expertise among the consultant workforce." ${ }_{13}$ In addition, health authorities have been reluctant to create new posts because of the financial implications. Doubts, expressed by the medical profession, have enabled the government to disguise its unwillingness to fund the recommended expansion.

Several separate developments may now result in a solution. Firstly, the juniors, believing their goals to have been stonewalled by the seniors, sought the direct action of the chairman of the NHS Management Board to solve the imbalance of the career structure. ${ }^{14}$ Secondly, both national and regional joint planning advisory committees have been instituted: these will advise the health authorities and universities on the acceptable number of junior posts, initially at senior registrar level, necessary to ensure a better career structure. Thirdly, changes in the rules governing the registration of foreign doctors have produced difficulties in the junior staffing of some district general hospitals, ${ }^{15}$ and the lack of applicants for posts with little training potential has forced one health authority to advertise in Europe for doctors to fill such posts. ${ }^{16}$ Finally, the former Minister for Health, Mr Barney Hayhoe, took the bull by the horns, chairing a joint DHSS/JCC working party, the deliberations of which resulted in Hospital Medical Staffing: Achieving a Balance. ${ }^{1}$

\section{DIFFICULT BALANCE}

The two sides of the manpower equation are difficult, although not impossible, to balance. Junior hospital doctors desire a better and more honest career structure than now exists; senior hospital $\underline{ }$ staff do not wish there to be a massive expansion of their numbers at the expense of their supporting junior staff. The recommendations in the document help to solve the equation.

Some new general surgical consultant posts are to be created by special funding. Although such funding is welcome, there are well founded anxieties that the amount per post is inadequate. Additional posts would be created not only by offering early retirement $\$$ (with full pension benefits) or part time contracts to seniorm consultants but also by converting some of the senior registrar posts? surplus to training requirements into consultant positions. Neither $\vec{F}$ of these latter two options would be costly since, as the document $\frac{\text { क }}{9}$ points out, the salaries for the new posts would be funded largely by the salaries released by early retirement of consultant staff and the $\frac{\overline{-}}{\bar{N}}$ reduction of senior registrar numbers. The creation of new consult $-\frac{5}{D}$ ant posts, which until this year has been negligible in general $\stackrel{\mathbb{}}{\varrho}$ surgery, is to continue at $2 \%$ a year. Thus with the present establishment of 947 consultant general surgeons increased by $\vec{\circ}$ perhaps 25 specially funded posts (some of the 50 specially funded posts are to be in the specialty of trauma and orthopaedics) and with $\vec{\omega}$ a cumulative $2 \%$ a year expansion, the establishment of consultant general surgeons in five years should number at least 1070. This 3 estimate does not include the unknown quantity of extra consultantiv posts to be created by early retirement and conversion of surplus $\stackrel{\omega}{\omega}$ senior registrar posts.

The manpower initiative proposes to streamline the careerG structure for junior doctors by equating not only senior registrar:but, in time, "career" registrar posts to the number of expected consultant vacancies. Once a "career" registrar post is obtained (the contract to be held by regional health authorities) the appointee may be reasonably sure that he or she will obtain a consultant post. The sluice gate allowing entry into a surgical career will in the future beo at the end of a slightly longer senior house officer training. We believe that this is fair and should prevent some young doctors, with $\bar{\square}$ few prospects of reaching consultancy, from wasting their early career in an oversubscribed specialty. We also approve the emphasis $\vec{\bullet}$ given to the proposals for more career counselling for junioroo doctors. Formal discussions with postgraduate deans, regional advisors, and district tutors, in addition to individual consultants, should improve the ad hoc system of career advice that pertains at present.

Registrar posts not allocated to "career" junior surgeons will be reserved, ideally through royal college sponsorship schemes, for the $\varrho$ short term training of overseas doctors who will return to their $\overrightarrow{\overrightarrow{0}}$ country. Contracts for these latter posts will be held at district level. 3 The training quality of all registrar posts will be monitored by the royal colleges and both "career" surgical registrars and overseas? registrars should be able to occupy posts on the same surgical rotations.

\section{PROPOSED NEW CAREER GRADE}

One of the more contentious issues in the document is the proposed new intermediate level career grade. Many doctors $\mathrm{N}$ already remain in junior posts for a considerable time with few or no $\mathrm{G}$ career prospects, ${ }^{17}$ and it is recognised that they undertake a large $\frac{D}{0}$ proportion of elective and emergency patient care. ${ }^{1318}$ Until now these doctors have had no job security. Despite the reservations of 0 some, we believe that this new grade will have its attractions for a proportion of doctors who genuinely do not wish to have the service, teaching, and research responsibilities associated with a consultanto contract but who wish to continue a career within the hospital $\bar{\varnothing}$ service, perhaps on a part time basis. We believe that the full time $\stackrel{\text { ? }}{+}$ salary of this post should not be dissimilar to that of a principal in $\frac{0}{T}$ general practice. Continual and careful planning of the responsibilities of each appointee to this new grade will be necessary in order $\stackrel{\mathbb{P}}{\stackrel{9}{\oplus}}$ to ensure that the post retains its professional attraction. Health $\stackrel{\mathbb{\triangle}}{\mathbb{Q}}$ authorities will have to be deterred from using these appointments in order to avoid expanding the consultant grade.

Consultant surgeons require reasonable junior support and are응 naturally resistant to current working patterns being changed by 


\section{EC's general practice directive a landmark}

It is largely owing to the work of the European Union of General Practitioners that a European Community directive on specific training for general practice has finally been achieved. Work started 16 years ago and the retiring president of the union, Dr Alan Rowe, is pleased that the directive was adopted by the Council of Ministers in the last months of the United Kingdom presidency. At its recent meeting the union had welcomed the directive, was satisfied that it retained the fundamental principles on which the union believed specific training should be based, and reaffirmed its view that the specific training should be undertaken after the acquisition of qualifications for the right to practise.

Dr Rowe told the BMA's Committee on the EEC last week that the directive was a landmark but it also represented a compromise. A minimum of two years' specific training was to be introduced by 1 January 1990 . The United Kingdom already has a three year training period but some countries, notably Belgium, do not. The full time two year course must be supervised by the competent authorities though these have not been defined. There must be six months in an approved medical practice and a minimum of six months in an approved hospital. From 1 January 1995 no general practitioner will be able to practise in a social security system in any member state unless he has acquired the training set out in the directive or equivalent training. Equivalent training has not been defined.

An important achievement is that the European Commission will have to report by 1 January 1997 on the implementation of the directive. At that time consideration will be given about whether to extend the regulations outside the social security system. The Advisory Committee on Medical Training will be asked to examine the system in each member state in due course.

Two other directives are important to the medical profession. Legislation to implement the directive on liability for defective products has to be on the statute book by July 1988 and Dr Rowe reported that the government intended to introduce a Bill within the next few months.

The suggestion for a directive for a general system for mutual recognition of higher education diplomas has been postponed but has not disappeared completely. Those professions who have directives would be excluded but the BMA has maintained that any general directive might dilute the provision for specific professional directives and did not contain a mechanism to guarantee the standard of training. The physiotherapists are one group that would be affected. Their representative, Mrs Caroline Poole, said that the Chartered Society of Physiotherapists was concerned that if activities rather than professions were to be egistered the way would be opened for fringe practitioners who might do some of the procedures undertaken by those registered with a professional body. If activities were to be limited the profession would become fossilised, particularly as there were to be no more professional advisory committees at European level to supervise training and standards.

The committee reiterated its support for the physiotherapists and other professions that might be affected by a general directive.

\section{Ethical code for Europe}

The Conférence des Ordres, which represents the regulatory bodies such as the General Medical Council, has been working on a European ethical text for the past 18 months. Mrs Heather Brown is one of the GMC's representatives on the conférence and she filled in the background. In 1985 a motion was tabled in the European parliament attacking the medical profession for being too protective and suggesting that the regulation of the profession should not be in the profession's hands. To counter this another motion suggested that the conference should produce an ethical text. The committee to which these motions were referred recommended that a council should be set up in each member state to draw up a patients' charter and to comment on ethical matters. The councils would be composed of members of the public, the legal profession, and one doctor.

In the light of this activity the conférence had

\section{Talking Point-continued from $p 1252$}

widespread reduction of junior staff. Under the new proposals there will be a reduction in the total number of junior supporting staff, but the document indicates that there will be provision for adequate numbers of intermediate level staff (from experienced senior house officer to senior registrar) to provide consultant staff with 24 hour emergency support. We believe that these proposals will result in a welcome change in the working practice of consultants as well as junior surgeons. We envisage that, with the increased number of consultants and reduced tiers of junior support, consultant surgeons may work in firms of two, sharing a surgical trainee. The direct responsibility of the consultant for emergency work might change, depending on the experience of the junior staff, while the frequency of days on take might be expected to diminish.

Most surgeons in training now spend two years undertaking research towards a thesis. The need for this has been questioned recently. ${ }^{19}$ We doubt whether the proposed reduction in honorary registrar contracts will reduce the number of junior surgeons undertaking this activity or shorten the length of training as market forces will encourage the career minded to build up an impressive curriculum vitae before applying for the sought after regional ("career") registrar posts.

The scope and practice of general surgery have changed greatly since 1948 , but since that time there has been no adjustment in the career structure of the specialty. Those in senior posts can continue to show their ability to adapt their working practices by allowing the junior staff, whom they have been happy to appoint, to share the benefits of a career appointment both in and outside the NHS Junior staff must recognise that in return for a better career structure at registrar level and above than existed previously competition will be intense during senior house officer training for the limited number of "career" registrar posts. When fully operational the proposals will result in a more ordered career structure for junior surgeons, but there will be much hardship suffered by those currently occupying registrar and junior research posts, for whom the career prospects are particularly bleak. Neither the proposals nor the existing terms of contract address this vexing matter.

We believe, however, that the package of proposals outlined in the manpower initiative is both timely and necessary and ultimately should help to correct the longstanding imbalance in the hospital career structure in a manner acceptable to the majority of the profession.

We thank Mrs Brenda Carter for typing the manuscript.

\section{References}

1 Department of Health and Social Security, Joint Consultants Committee, chairmen of regional health authorities. Hospital medical staffing: achieving a balance. London: DHSS, 1986.

2 Hospital Junior Staff Committee of the BMA. The manpower crisis in medicine-an explanation. London: HJSC 1985.

3 Royal College of Surgeons of England. Second report on surgical manpower and the career structure. London: Royal College of Surgeons of England, 1982.

4 Taylor I, Clyne CAC. Senior registrar applications in general surgery in 1982 and 1985 . Br Med f 1985;291:143-4.

5 Department of Health and Social Security. Medical staffing and prospects in the NHS in England and Wales, 1978. Health Trends 1979;11:53-7.

6 Department of Health and Social Security. Medical and dental staffing prospects in the NHS in England and Wales, 1983. Health Trends 1983;16:25-9.

Department of Health and Social Security. Medical and dental staffing prospects in the NHS in England and Wales, 1984. Health Trends 1985;17:45-52.

8 Royal College of Surgeons of England. 1985 higher surgical training census. London: Royal College of Surgeons of England, 1985 .

9 Dehn TCB, Blacklay PF, Taylor GW. A survey of registrars undertaking general surgical research in the United Kingdom on 1 October 1983. Br f Surg 1985;72:668-71.

10 Royal College of Surgeons of England. Report on surgical manpower and the careet structure. London: Royal College of Surgeons of England, 1981.

11 Johnson JN. Cycle of gloom over manpower. Br Med f 1985;291:361-2.

12 Social Services Committee. Fourth report. Medical education with special reference to the number of doctors and the career structure in hospitals. London: HMSO, 1981. (Short report.)

13 Department of Health and Social Security. Government response to the fifth report from the social services committee, 1984-85 session. London: HMSO, 1986.

14 Anonymous. Annual hospital conferences. BrMed f 1985;290:1843-4.

15 Woodyard JE. Orthopaedic junior staff. BrMed f 1986;292:902

16 Anonymous. Hospital seeks doctors from the continent. The Times 1986 May 6:3.

17 Todd G, O'Brien M, Gooding D. Career structure-the modern doctors' dilemma. Br Med $\mathrm{f}$ 1985;291:755-6.

18 National Association of Health Authorities in England and Wales. Medical manpower planning in the NHS. Birmingham: NAHA, 1985.

19 Treasure T. Need all young surgeons be masters? Br f Hosp Med 1986;36:163. 
prepared a draft, and another GMC representative, Sir Henry Yellowlees, had helped to produce a consensus report by the members. This draft will be considered by the GMC at its next meeting and if approved will go back to the Conférence des Ordres in 1987. The text includes a set of principles that the conférence believes each member state could apply as appropriate.

\section{Pay parity for clinical academic staff}

The pay of clinical academic staff is to be increased in line with that of NHS doctors and dentists, who received an average increase of $5 \cdot 7 \%$ from 1 July 1986. At a meeting on 31 October of the Clinical Academic Staff Salaries Committee (CASSC) it was announced that the Committee of Vice Chancellors and Principals had authorised the CASSC to go ahead. This is the committee that translates the NHS pay awards, recommended by the doctors' and dentists' review body, to clinical academic staff. Clinical academic staff should soon receive notification of the increase, backdated to 1 July.

Clinical academic staff have had pay parity with their NHS colleagues since 1968 but on several occasions in recent years delays in payment have occurred because of the government's reluctance to provide the University Grants Committee with the extra funds needed. This year's long delayed agreement follows persistent parliamentary activity by the BMA and the British Dental Association. While the pay award for 1986 has been secured, the funding of future pay awards for clinical academic staff remains uncertain. The CASSC will be considering how best to secure payment in the future.

\section{DHSS roadshow discusses patients' complaints}

\section{"Vigorous and constructive" was how Mr Tony Newton described the public consultations that have been taking place on the government's pri- mary health care discussion document. ${ }^{1} \mathrm{He}$ made would lead to unnecessary formality." \\ Informal procedures favoured} the comment when opening one such meeting in London on 28 October. The subject was complaints procedures, and, as with the previous consultant "roadshows," the audience was composed mainly of members of the organisations that had been invited to give evidence.

The General Medical Services Committee, which was strongly represented, has already criticised the Department of Health for bringing out a consultation document on complaints ${ }^{2}$ during the discussion period on primary health care. At its last meeting there was a full debate, ${ }^{3}$ and a commentary is going to the special conference of representatives of local medical committees on 13 November. In one day representatives will have to decide policy on primary health care, neighbourhood nursing, and complaints procedures.

The form of the countrywide DHSS roadshows is that one member of a "special interest" team is invited to speak for five minutes, leaving time for discussion in the allotted half an hour. Dr David
Williams, who chairs the GMSC subcommittee that studied the DHSS's consultation document, opened the committee's case by pointing out that the general practitioner's special conference would advise the committee on which line to take in negotiations on complaints, so the media reports that the GMSC had rejected the proposals were untrue. He described the service committee procedure as an uneasy compromise. "Patients think of it as a complaints machinery. But the DHSS notes of guidance make it clear that it does not exist to remedy patients' personal grievances but to decide whether doctors have fulfilled the terms of contract. No wonder patients do not always understand the system. Doctors think of it as a disciplinary system. Yet the DHSS notes tell us that it is, primarily, a method of inquiry. The penalties imposed are not fines but withholdings of income. But the withholdings are related to the seriousness of the breach-as if they were fines-and not to the financial consequences of the breach, like civil damages. No wonder doctors do not understand the system."

By combining a fact finding inquiry with a disciplinary hearing, Dr Williams said, anomalies had been created. The government's proposals had introduced legal processes and professional advocacy and would invest what was in theory a domestic committee with the mantle of a court. The GMSC believed that an extension of informal conciliation offered the most sensible solution.

Dr Williams suggested to $\mathrm{Mr}$ Tony Newton and his team that the administrator should be empowered under the regulations, and subject to the consent of both the complainant and the respondents, to refer any complaint for informal conciliation by one lay person and one doctor, appointed by the family practitioner committee. They, in turn, should be empowered to refer any case they considered unsuitable for conciliation to the chairman of the service committee, who would then determine whether the complaint involved a breach of the terms of service.

The Minister for Health thought that the general practitioners were criticising the existing system as much as his department's proposals. What particular objections did they have to the government's proposals?

Allowing a paid advocate, Dr Alistair Riddell told him, would be going down a slippery slope because it would have to be allowed on both sides. As the GMSC has stated in its document to the special conference, "the balanced approach of service committees depends upon the absence of paid advocates. The introduction of paid advocates

Asked how the procedure could be improved, Dr Williams hoped that it could be emphasised to patients that there was no bar to their seeing their doctor to talk about any complaint they might have. There had to be an informal procedure that was seen to be fair to both sides and the procedure should be made less daunting. Here, Dr Williams believed, the chairman of the service committee played an important part.

The next witness, the Association of Community Health Councils in England and Wales, also supported an informal conciliation procedure. The association's spokesman, Mrs Wyn Pockett, said that many patients believed that the system was weighted against them and that the restrictive time limit for submitting complaints was unhelpful.

At present complaints have to be made within eight weeks, and the government has proposed an extension to 13 weeks. This is supported by the community health councils but opposed by the general practitioners.

Family practitioners should be allowed to make decisions and call for documents and summon witnesses, Mrs Pockett suggested. The association's one objection to the consultation document was the suggestion that a member of parliament should act as the complainants's friend. He should not do so if he was a lawyer, the association believed.

Mr Newton saw that was a little unfair to those constituencies served by a lawyer member.

As to improving the system, it was suggested that better communication between general practitioners and their patients would avoid many service committee cases. Most patients did not want to go as far as that. They wanted a satisfactory explanation to their complaint and so prevent the same thing happening to someone else. That said, there should be wider publicity given-perhaps via surgery posters-about the service committee procedure, but this did not have to be couched in such a way as to encourage complaints.

\section{References}

1 Department of Health and Social Security. Primary health care: an agenda for discussion. London: HMSO, 1986. (Cmnd 9771.)

2 Department of Health and Social Security. Family practitioner services. Complaints investigation procedures. London: DHSS, 1986.

Anonymous. Response to "complaints investigation procedures." BrMed f 1986;293:1115-6.

\section{Loss of revenue for forensic pathologists}

Forensic pathologists who provide vital clinical evidence to the police, coroners, and courts in London are not being paid for being on call and available 24 hours a day. In the rest of England and Wales pathologists reached an agreement in 1981 that introduced a uniform system of payment of an annual availability fee and call out fees. The availability fee recognised that the risk of violent crime being committed meant that it was essential for a pathologist to be available and on call at all times. In London, where forensic pathologists help the police with around 450 suspicious deaths a year, there are different contractual arrangements. The BMA has written to Mr Gordon Wasserman, who is chairing a Home Office review into the provision of a forensic pathology service in England and Wales. He has been asked to agree that there should be no further delay in paying forensic pathologists in the metropolitan area and that this should not wait until his inquiry has reported.

\section{BMA's south Thames regional office}

A new regional office to serve the south east and south west Thames regions will open on 28 November at Downlands House, 15 High Street, Purley, Surrey CR2 2XA. Tel: 016605558. The regional officer, Mrs Carol Burnard, and the industrial relations officers for south west Thames, Mrs Jane Nicholls, and for south east Thames, $M$ Philip Tucker, will work from the Purley office.

BMA Services staff who work for the two regions will also move to Purley. Tel: 016605537.

The locum service bureau will remain in BMA House. Tel: 013878611 or 013871844. 